\title{
Aspiração de corpo estranho em pediatria: uma emergência - relato de caso
}

\author{
Strange body aspiration in pediatrics: an emergency - case report
}

Aspiración de cuerpo extraño en pediatría: una emergencia - relato de caso

Caroline Cunha da Rocha ${ }^{1 *}$, Cristine Bessa Gondim², Yana Montezuma Santos ${ }^{2}$, Myriam Ruth da Silva Magalhães ${ }^{3}$, Liter William Pinheiro Nunez ${ }^{1}$.

\section{RESUMO}

Introdução: Corpo estranho (CE) é qualquer objeto solido ou liquido que de forma acidental ou intencional possa penetrar o corpo ou suas cavidades. Habitualmente, o CE é ingerido ou colocado pela criança nas narinas e ouvido, apresentando um risco maior quando é aspirado para via aérea inferior. A obstrução de vias aéreas superiores predomina em menores de 5 anos, sendo $65 \%$ menores de 1 ano. A Fibrobroncoscopia (FB) rígida tem sua importância no diagnóstico e na retirada de CE. Detalhamento do caso: Paciente, 7 anos, sexo masculino, deu entrada em serviço de urgência e emergência pediátrica apresentando disfagia, tosse seca persistente e cansaço há aproximadamente 12 horas, associado à aspiração de CE (caroço de ingá). Ao exame físico encontrava-se em regular estado geral, dispneico com uso de musculatura subcostal, tosse estridulosa, hidratado e afebril ao toque. $\mathrm{Na}$ ausculta pulmonar presença de sibilos dispersos. Paciente manteve tosse persistente e evoluiu com febre após 48 horas de entrada no serviço. Na tomografia de tórax foi identificado $\mathrm{CE}$ em traqueia na altura de brônquio fonte esquerdo. Paciente realizou antibióticoterapia seguida de remoção de corpo estranho via broncoscopia flexível e recebeu alta após 48 horas com quadro respiratório melhorado. Discussão: A aspiração de corpo estranho (CE) é um acidente grave na medicina e potencialmente fatal, em crianças de todas as idades mas principalmente em crianças com menos de três anos. A broncoscopia é o exame ideal por ser diagnóstico e terapêuticos e deve ser realizada nos casos sintomáticos suspeitos. A prevenção é o melhor método para diminuição do risco de óbito por esse tipo de agravo.

Palavras-chave: Corpo estranho, Aspiração, Pediatria, Emergência.

\begin{abstract}
Introduction: Foreign body (FB) is any solid or liquid that can penetrate the body or its cavities. It is usually ingested or inserted by the child in the nostrils and ears, with greater risk when aspirated to the inferior airway. The upper airway obstruction predominates in children under 5 years of age, and $65 \%$ of these are under 1 year or less. Rigid Fibrobronchoscopy (RF) is important in the diagnosis and withdrawal of FB. Case report: 7 year-old male patient admitted to pediatria emergency department presenting dysphagia, persistent dry cough and tiredness for about 12 hours, associated with aspiration of FB (ingá seed). Physical examination shows regular state, dyspneic with use of subcostal muscles, stridulous cough, hydrated and afebrile. pulmonary auscultation showed wheezing. Patient maintained persistent cough and started fever after 48 hours of assistance. Chest tomography identified FB in the trachea, near the left bronchus. Patient underwent antibiotic therapy followed by removal of foreign body via flexible bronchoscopy and was discharged after 48 hours with improved respiratory condition. Discussion: FB aspiration is a serious medical situation and potentially fatal in children of all ages, especially children under the age of three. RF is the ideal exam for it is diagnostic and therapeutic and should be performed in suspected symptomatic cases. Prevention is the best method to reduce the risk of death from this type of condition.
\end{abstract}

Keywords: Foreign body, Aspiration, Pediatrics, Emergency.

\footnotetext{
${ }_{1}^{1}$ Pronto Socorro Municipal de Belém Mário Pinotti. *E-mail: carolinegatti@gmail.com

2 Fundação Santa Casa de Misericórdia do Pará.

${ }^{3}$ Hospital Universitário Joao de Barros Barreto.
}

SUBMETIDO EM: 10/2018

ACEITO EM: 11/2018

PUBLICADO EM: $1 / 2019$ 


\section{RESUMEN}

Introducción: un cuerpo extraño (CE) es cualquier objeto o líquido Que pueda penetrar el cuerpo o sus cavidades. Se suele ingerir o colocarse por el niño en lãs fosas nasales y oídos, presentando un riesgo más importante cuando se aspira al segmento inferior de la vía aérea. La obsctrución de las vías aéreas ocurre principalmente en los niños de 5 años de edad, y el 65\% de estos están bajo un año de edad. La fibrobroncoscopía rígida (FR) tiene importancia en el diagnóstico y la retirada de CE. Caso clínico: Paciente de 7 años, varón, ingresado en el servicio de urgencias y emergencia pediátrica con disfagia, tos persistente y cansancio respiratório durante aproximadamente 12 horas, asociado a aspiración de CE (semilla de ingá). El examen físico mostró regular estado, disnea con uso de músculos subcostales, tos estridulenta, hidratado y afebril al tacto. En la auscultación pulmonar, presencia de sibilancias. El paciente mantuvo tos persistente y progresó con fiebre después de 48 horas de asistencia. La tomografía de tórax identificó CE en la tráquea, cerca del bronquio izquierdo. El paciente fue sometió a tratamiento con antibióticos seguido de la extirpación del cuerpo extraño mediante broncoscopia flexible y dispensado del hospital después de 48 horas con mejoría de la condición respiratoria. Discusión: La aspiración de cuerpo extraño (CE) es un accidente médico grave y potencialmente mortal en niños de todas las edades, especialmente en niños bajo tres años. La FR es el examen ideal porque es diagnóstico y terapéutico y se debe realizar en casos sintomáticos sospechosos. La prevención es el mejor método para reducir el riesgo de muerte por este tipo de condición.

Palabras clave: Cuerpo extraño, Aspiración, Pediatría, Emergencia.

\section{INTRODUÇÃO}

Corpo estranho (CE) é qualquer objeto sólido ou líquido que de forma acidental pode penetrar o corpo ou suas cavidades. Habitualmente é ingerido ou colocado pela criança nas narinas e ouvido, mas apresenta um risco maior quando é aspirado para via aérea inferior (WAKSMAN et al, 2005; FRAGA et al, 2008; JUNIOR et al, 2017). Qualquer material pode se tornar um CE no sistema respiratório, os mais comuns que tem sido relatado são os vegetais, caroço ou semente de frutas, grãos e brinquedos. O médico pode suspeitar de obstrução de vias aéreas por corpo estranho quando houver aparecimento abrupto de sibilância (podendo ser o primeiro sinal), estridor (sendo este sintomas uns dos principais), tosse, cansaço e broncoespasmo na ausência de febre ou sintomas que cause suspeição anteriormente (FRAGA et all, 2008; JUNIOR et al, 2017; GONÇALVES et al, 2011; MELO et al, 2015; RODRIGUES et al 2016). A percepção dos primeiros sintomas podem passar desapercebidos, já que cerca de $40 \%$ podem estar assintomáticos (FRAGA et al, 2008). Em geral, os episódios de engasgo podem ocorrer durante a alimentação ou brincadeira e que na maioria das vezes não foi observado pelos pais ou pessoas que acompanham as crianças (WAKSMAN et al, 2005; RODRIGUES et al, 2016; LA TORRE et al, 2013). Este agravo na maioria das vezes pode ser evitado, estando a aspiração de corpo estranho entre os $1 / 3$ dos acidentes que acometem as crianças em (WAKSMAN et al, 2005).

A obstrução de vias aéreas superiores em um estudo ( $n$ : 69) predominou no sexo masculino em $67,5 \%$ (FRAGA et al, 2008). A prevalência fica em torno de 65 a $80 \%$ dos casos em menores de 5 anos e na faixa etária de 5 a 7 anos chega a cerca de 38\% (JUNIOR et al, 2017; GONÇALVES et al, 2011; FILOCOMO et al, 2017). Os líquidos são responsáveis pela obstrução na maioria dos casos, porém pequenos objetos como balões e alimentos (salsichas, castanhas, uvas) podem obstruir a via aérea em crianças (FRAGA et al, 2008; JUNIOR et al, 2017). Nos Estados Unidos as estatísticas apontam que o corpo estranho chega a ser responsável por $5 \%$ dos óbitos em menores de 5 anos (FRAGA et al, 2008). No Brasil a aspiração por corpo estranho está entre a terceira e a quinta de morte por este tipo de acidente (JUNIOR et al, 2017; GONÇALVES et al, 2011). Os diagnósticos diferenciais de aspiração de corpo estranho são: crupe viral, edema angioneurótico, traqueíte bacteriana, abscesso retrofaríngeo ou peritonsilar, mononucleose infecciosa, traqueíte bacteriana e supraglotite infecciosa (WAKSMAN et al, 2005).

A radiografia de tórax é na maioria das vezes o primeiro exame de imagem a ser realizado. Em casos de objetos radiopacos, estes podem ser visualizados em cerca de $75 \%$ dos casos, porém uma radiografia normal não afasta a hipótese de aspiração de CE. Os achados mais comumente encontrados são atelectasia e 
hiperinsuflação (FRAGA et al, 2008; GONÇALVES et al, 2011; RODRIGUES et al, 2016; BITTENCOURT E CAMARGO, 2002).

A Fibrobroncoscopia (FB) independente de exames radiológicos normais deve ser realizada na suspeita de aspiração de CE realizada via endoscópica com o broncoscópio de tubo aberto rígido ou flexível sob visualização direta para diagnóstico e sendo também utilizado como terapêutica na retirada de CE e auxiliando na redução da mortalidade e do tempo de internação hospitalar (WAKSMAN et al, 2005; FRAGA et al, 2008; GONÇALVES et al, 2011; MELO et al, 2015; RODRIGUES et al, 2016; BITTENCOURT E CAMARGO, 2002).

\section{DETALHAMENTO DO CASO}

Paciente, 7 anos, sexo masculino, deu entrada em serviço de urgência e emergência pediátrica apresentando disfagia, tosse seca persistente e cansaço há aproximadamente 12 horas, associado à aspiração de CE (caroço de ingá). Ao exame físico encontrava-se em regular estado geral, dispneico com uso de musculatura subcostal, tosse estridulosa, hidratado e afebril ao toque. Na ausculta pulmonar sibilos dispersos, sem hipoxemia. Menor realizou radiografia de tórax evidenciando apenas leve infiltrado inflamatório difuso (Imagem 1). Foi acionado serviço de broncoscopia que realizou procedimento sob sedação em centro cirúrgico, neste procedimento não foi identificado corpo estranho. Menor manteve tosse persistente e evoluiu com febre após 48 horas de entrada no serviço. Foi realizado nova radiografia de tórax evidenciando opacidade em pulmão esquerdo (Imagem 2, seta vermelha) e hemograma apresentando leucocitose com desvio a esquerda. Foi realizado tomografia de tórax sendo identificado $\mathrm{CE}$ em traqueia na altura de brônquio fonte esquerdo (Imagem 3, seta vermelha). Iniciou-se Clindamicina + Ampicilina para tratamento de pneumonite química e acionado novamente serviço de broncoscopia, nesta segunda abordagem foi retirada a casca da semente de ingá, não tendo sucesso na retirada total do CE. Menor evoluiu com melhora discreta da tosse, porém com melhora significativa dos parâmetros laboratoriais de leucocitose e de radiografia de tórax (Imagem 4) após 5 dias de antibióticos. Foi solicitado transferência para hospital de referência em broncoscopia flexível para nova abordagem broncoscópica. Menor realizou procedimento de broncoscopia com broncoscópio flexível sob sedação em bloco cirúrgico e sendo realizado retirada de $100 \%$ CE de brônquio (Imagem 5, 6). Paciente evolui com melhora total da tosse, recebendo alta após 48 horas da última broncoscopia.

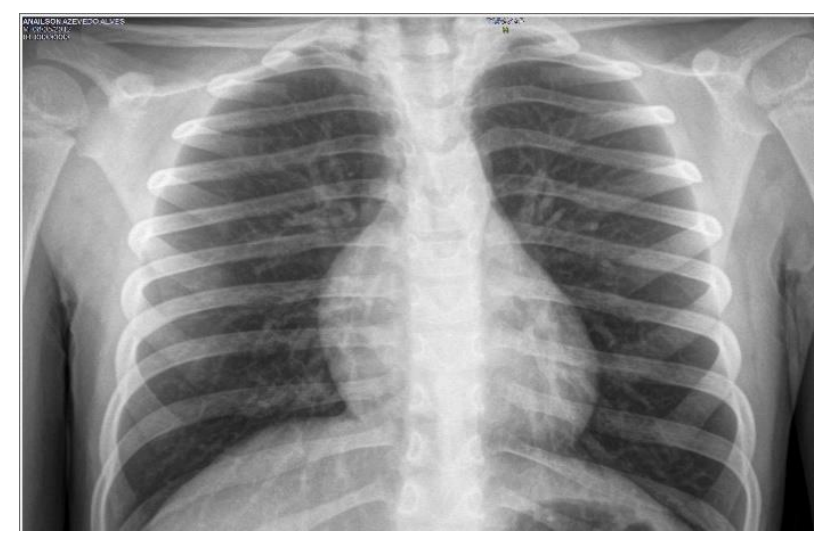

Imagem 1: Radiografia de tórax de entrada demonstrando hiperinsuflação e retificação dos arcos coistais. Fonte: Arquivo radiológico Pronto Socorro Municipal Mario Pinotti.

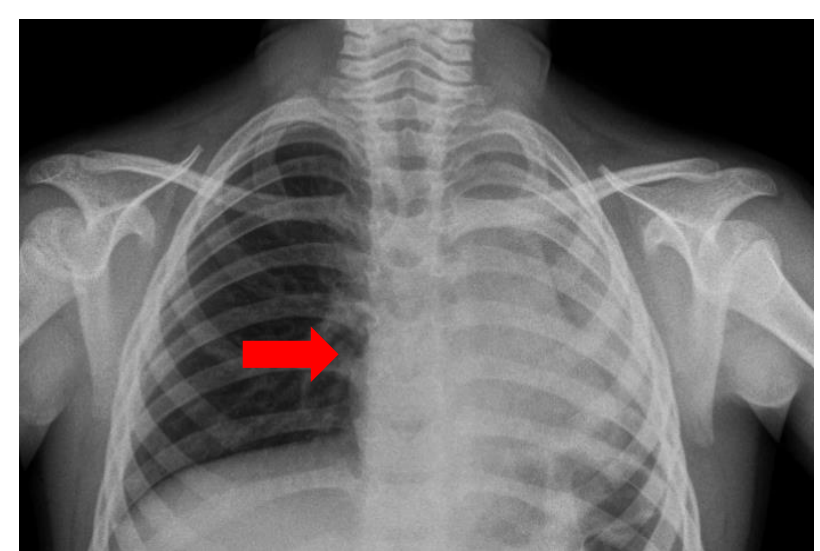

Imagem 2: Radiografia de tórax evidenciando opacidade em pulmão esquerdo. Fonte: Arquivo radiológico Pronto Socorro Municipal Mario Pinotti. 


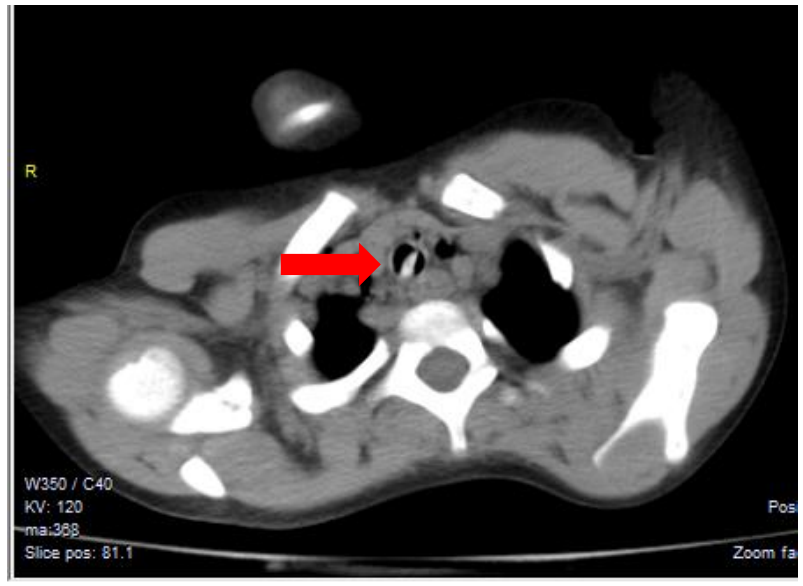

Imagem 3: Tomografia de tórax sendo identificado $\mathrm{CE}$ em traqueia na altura de brônquio fonte esquerdo. Fonte: Arquivo radiológico Pronto Socorro Municipal Mario Pinotti.

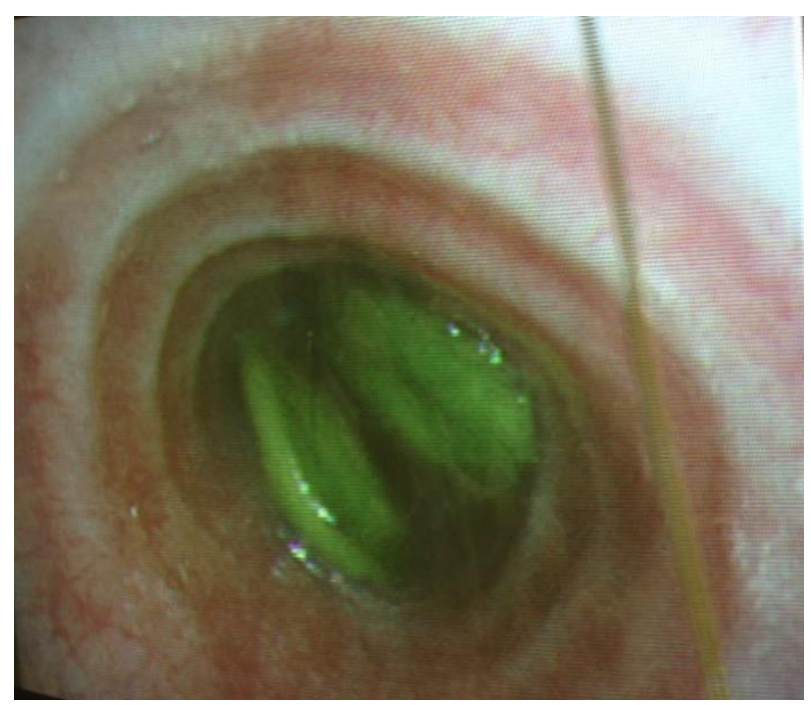

Imagem 5: Broncoscopia evidenciando corpo estranho em brônquio fonte. Fonte: Arquivo radiológico Fundação Santa Casa de Misericórdia.

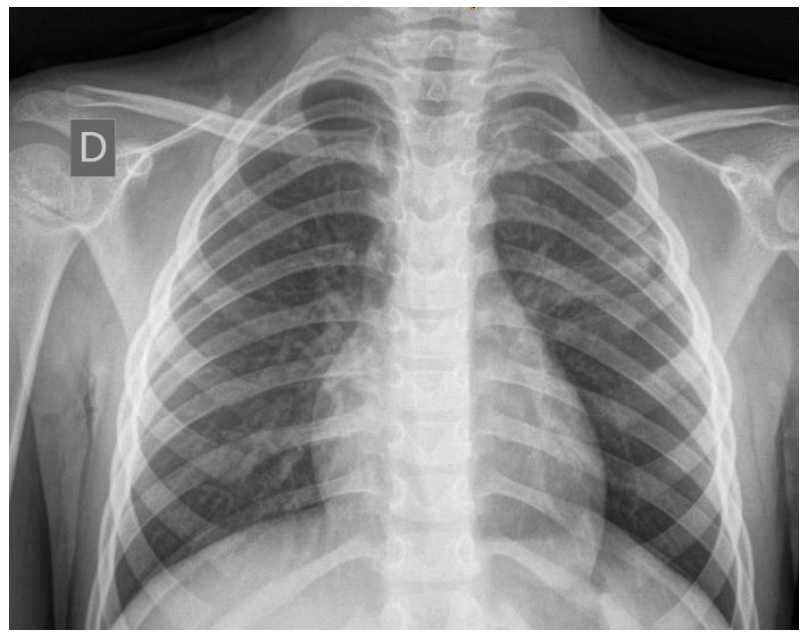

Imagem 4: Radiografia de tórax após 5 dias de antibiótico. Fonte: Arquivo radiológico Pronto Socorro Municipal Mario Pinotti.

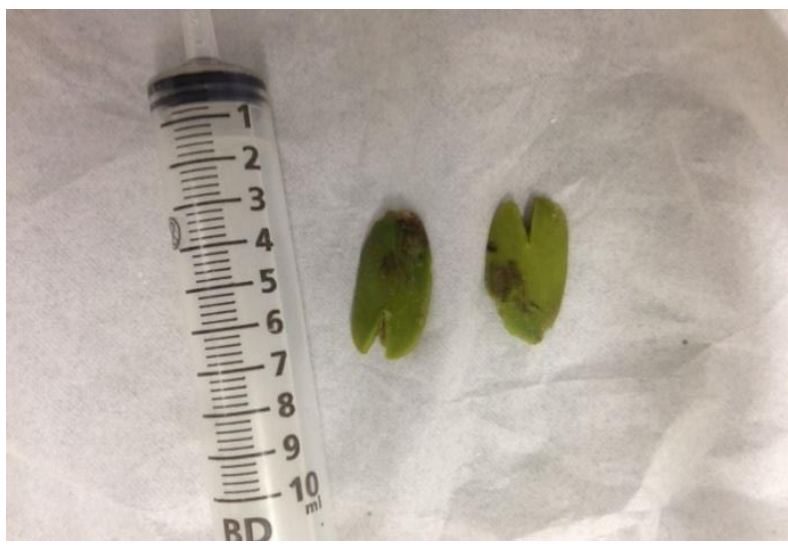

Imagem 6: Imagem 6: corpo estranho retirado de brônquio, aproximadamente $1,5 \mathrm{~cm}$ de comprimento. Fonte: Arquivo radiológico Fundação Santa Casa de Misericórdia.

\section{DISCUSSÃO}

A aspiração de corpo estranho (CE) é um tipo de emergência médica de ameaça a com altas taxas de morbilidade. É difícil reconhecer em crianças pequenas e sem testemunhas a aspiração de um $\mathrm{CE}$, o que eleva o índice de suspeição de aspiração (FRAGA et al, 2005). O paciente em questão é do sexo masculino cujo gênero é o mais acometido segundo literatura, chegando a $73 \%$ na Holanda (BITTENCOURT E CAMARGO, 2002). O próprio paciente informou que estava se alimentado da fruta e que durante deglutição acabou aspirando o caroço da fruta. No caso os achados clínicos incluíram tosse estridulosa persistente, disfagia e sibilos difusos à auscultação pulmonar, sendo a tosse o sintoma mais frequente chegando a 75,4\% dos casos o estridor como o de maior significado preditor de obstrução de vias aéreas inferiores (FRAGA et al, 2005). Mas é importante estar atento que $40 \%$ dos pacientes podem estar assintomáticos e sem alterações ao exame físico (FRAGA et al, 2005). A radiografia do tórax permite a visualização de corpos estranhos radiopacos em cerca de $75 \%$ dos casos e podem estar normais em média de 12,5 a $25,6 \%$, como paciente em questão foi possível visualizar hiperinsuflação e retificação dos arcos costais (RODRIGUES et al, 2016; 
FRAGA et al, 2005). A tomografia de tórax foi fundamental para o diagnóstico e a utilização do broncoscópio rígido inicialmente permitiu uma melhor visualização direta com localização em brônquio fonte esquerdo e depois submetido a broncoscopia flexível para retirada do CE. Cerca de apenas 36,7\% (n: 80 ) dos casos de aspiração de CE foram encontrados nesta localização anatômica, demostrando a raridade por esta seletividade (FRAGA et al, 2005). Após o atendimento inicial cerca de $93,5 \%$ recebem alta logo nas primeiras 24 horas segundo estatística de um estudo com n: 114, embora no mesmo estudo um percentual de $14 \%$ ficou internado por esta causa, podendo-se concluir que o atendimento inicial realizado de forma correta e precoce com os recursos adequados proporcionam bom prognóstico mesmo diante da gravidade deste tipo de acidente (FRAGA et al, 2005). Não foi encontrado dados estatísticos sobre o percentual ou número de óbitos no Brasil por esta entidade citando apenas como uma terceira causa de óbito, o que pode configurar uma subnotificação dos casos. Na literatura consultada, em quase todas da referência deste artigo citam como importante causa de óbito. Desde a introdução das técnicas do Suporte Básico de Vida em Pediatria em 1988, os óbitos por esta causa reduziram em 60\% nos EUA (FRAGA et al, 2005). Desta maneira, uma história clínica de início súbito de tosse, estridor persistente, alterações na auscultação pulmonar com assimetria e da ausência de alterações na radiografia de tórax, pode e deve fazer o médico suspeitar de CE e iniciar imediatamente condutas para seu diagnóstico e tratamento incluindo entre eles a broncoscopia. JUNIOR et al, 2017; GONÇALVES et al, 2011; MELO et al, 2015). Assim podemos diminuir as taxas de morbimortalidade causadas por este tipo de acidente.

\section{CONCLUSÃO}

A aspiração de corpo estranho é uma emergência médica que deve ser prontamente atendida quando os critérios de sintomatologia forem suspeitados pois está relacionado a altas taxas de morbilidade, principalmente em crianças com menos de três anos. Radiografia de tórax continua como um dos primeiros exames de imagem sendo a grande maioria complementado com broncoscopia para diagnóstico definitivo e sendo também utilizada com terapêutica. A prevenção dos acidentes com aspiração de corpo estranho continua sendo a medida mais eficaz para evitar os altos índices de atendimentos hospitalares por esta causa.

\section{REFERÊNCIA}

1. WAKSMAN RD, GIKAS RMC, MACIEL WL. Crianças e Adolescentes seguros. Guia Completo para Prevenção de Acidentes e Violências. Sociedade Brasileira de Pediatria. Editora: Publifolha, 2005.

2. FRAGA AMA, REIS MC, ZAMBON MP, et all. Aspiração de corpo estranho em crianças: aspectos clínicos, radiológicos e tratamento broncoscópico. J Bras Pneumol. 2008;34(2):74-82

3. JUNIOR DC, SILVA LR, BORGES WG. Tratado de pediatria: Sociedade Brasileira de Pediatria. 4. ed. Barueri, SP: Manole, 2017.

4. GONÇALVES MEP, CARDOSO SR, RODRIGUES AJ. Corpo estranho em via aérea. Pulmão RJ 2011;20(2):5458.

5. MELO GVSB, FONTELES AS, ESMERALDO CUP, et all. Aspiração de corpo estranho em crianças: aspectos clínicos e radiológicos. Residência Pediátrica 2015;5(1):24-6

6. RODRIGUES M, TEIXEIRA J, NASCIMENTO P, et all. Aspiração de corpo estranho na criança: um perigo escondido. Nascer e Crescer 2016; 25(3): 173-6.

7. LA TORRE FPF, PASSARELLI MLB, CESAR RG, et all. Emergências em pediatria: protocolos da Santa Casa. 2. ed. Barueri, SP: Manole, 2013.

8. FILÓCOMO FR, HARADA MJ, MANTOVANI R, et all. Perfil dos acidentes na infância e adolescência atendidos em um hospital público. Acta Paul Enferm. 2017; 30(3):287-94.

9. BITTENCOURT PFS, CAMARGO PA. Aspiração de corpos estranhos. Jornal de Pediatria - Vol. 77, №1, 2002. 